\title{
Cu-Catalyzed Cross-Coupling of Nitroarenes with Aryl Boronic Acids to Construct Diarylamines.
}

\author{
Xinyu Guan and Tom G. Driver*
}

Department of Chemistry, University of Illinois at Chicago, 845 West Taylor Street, Chicago, Illinois 60607-7061, USA

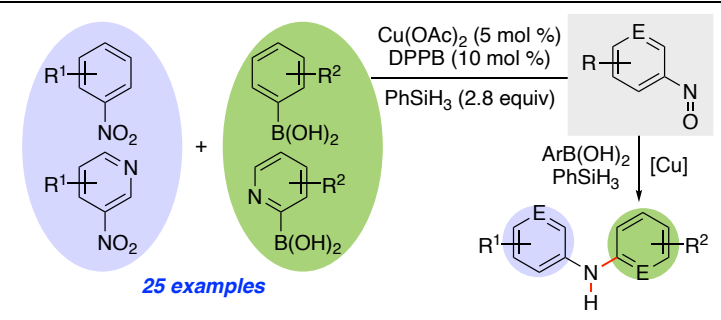

ABSTRACT. The development and study of a simple copper-catalyzed reaction of nitroarenes with aryl boronic acids to form diarylamines that uses phenyl silane as the stoichiometric terminal reductant is described. This cross-coupling reaction requires as little as $2 \mathrm{~mol} \%$ of $\mathrm{CuX}$ and $4 \mathrm{~mol} \%$ of diphosphine for success and tolerates a broad range of functional groups on either the nitroarene or the aryl boronic acid with to afford the amine in good yield. Mechanistic investigations established that the cross-coupling reaction proceeds via a nitrosoarene intermediate and that copper is required to catalyze both the deoxygenation of the nitroarene to afford the nitrosoarene and C-NAr bond formation of the nitrosoarene with the aryl boronic acid.

The ubiquitous nature of $N, N$-diaryl amines in molecules that exhibit important biological- and material activities has spurred considerable research in developing efficient catalytic reactions to construct this important scaffold. ${ }^{1,2}$ While transition metal-catalyzed cross-coupling reactions that form $\mathrm{C}-\mathrm{N}$ bonds are legion, ${ }^{3}$ few examples exist of their use to make secondary $N, N$-diaryl amines from nitroarenes. Our laboratory has developed a series of transition metal-catalyzed reactions that exploit the reactivity embedded in nitroarenes for the construction of C-NAr bonds via nitrosoarene reactive intermediates, ${ }^{4}$ and we were curious if a nitroarene could serve as the nitrogen component of the cross-coupling reaction. In 2002, Sapountzis and Knochel reported that diaryl amines 3 could be constructed from nitroarenes via the nucleophilic addition of Grignard reagents to nitrosoarenes followed by an iron-mediated reduction of the N-oxide product. ${ }^{5,6}$ After this seminal report, the development of reductive intermolecular cross-coupling reactions of nitroarenes lay dormant until 2015 when Baran and co-workers reported that $30 \mathrm{~mol} \%$ of $\mathrm{Fe}(\mathrm{acac})_{3}$ catalyzed a reductive hydroamination reaction between a nitroarene and an olefin using superstoichmetric amounts of $\mathrm{PhSiH}_{3}$ and $\mathrm{Zn}(0)$ as the reductant (Scheme 1). ${ }^{7}$ The authors proposed that this reaction occurred through the addition of benzyl radical 5 to nitrosoarene $\mathbf{1}$. For this reaction, the transition metal catalyst was not involved in the formation of the $\mathrm{C}-\mathrm{NAr}$ bond but functioned to facilitate deoxygenation of the nitroarene to the nitrosoarene. This report spurred a surge in interest in using nitroarenes to construct C-NAr bonds in reductive amination reactions. ${ }^{8}$ Recently, Radosevich and co-workers reported an organophosphorous-catalyzed reductive coupling of nitroarenes and aryl boronic acids using phenyl silane as the stoichiometric reductant. ${ }^{9}$ Critical to the success of this transformation was the strained nature of the phosphacyclobutane catalyst 6 , which enables the $\mathrm{P}(\mathrm{III})-\mathrm{P}(\mathrm{V})=\mathrm{O}$ redox manifold. ${ }^{9}$ In 2019, a Mo-catalyzed reductive coupling of nitroarenes and boronic acids that used triphenylphosphine as the terminal reductant was reported by Suazéz-Pantiga, Sanz and co-workers. ${ }^{10}$ This transformation required only 5 mol \% of $\mathrm{MoO}_{2} \mathrm{Cl}_{2}(\mathrm{dmf})_{2}$ and bipyridine and a slight excess of either an aryl- or alkyl boronic acid for success and was proposed by the authors to proceed via metallocycle 10. We hoped to build on these results by developing a catalytic system that used a commercially available and earth abundant first row transition metal and ligand and a mild reductant. Herein, we report the development of a $\mathrm{Cu}$-catalyzed cross-coupling reaction of nitroarenes and aryl boronic acids that uses phenyl silane as the stoichiometric reductant. Our data suggests that copper catalyzes both the deoxygenation of nitroarene to nitrosoarene and subsequent formation of the $\mathrm{C}-\mathrm{NAr}$ bond. 

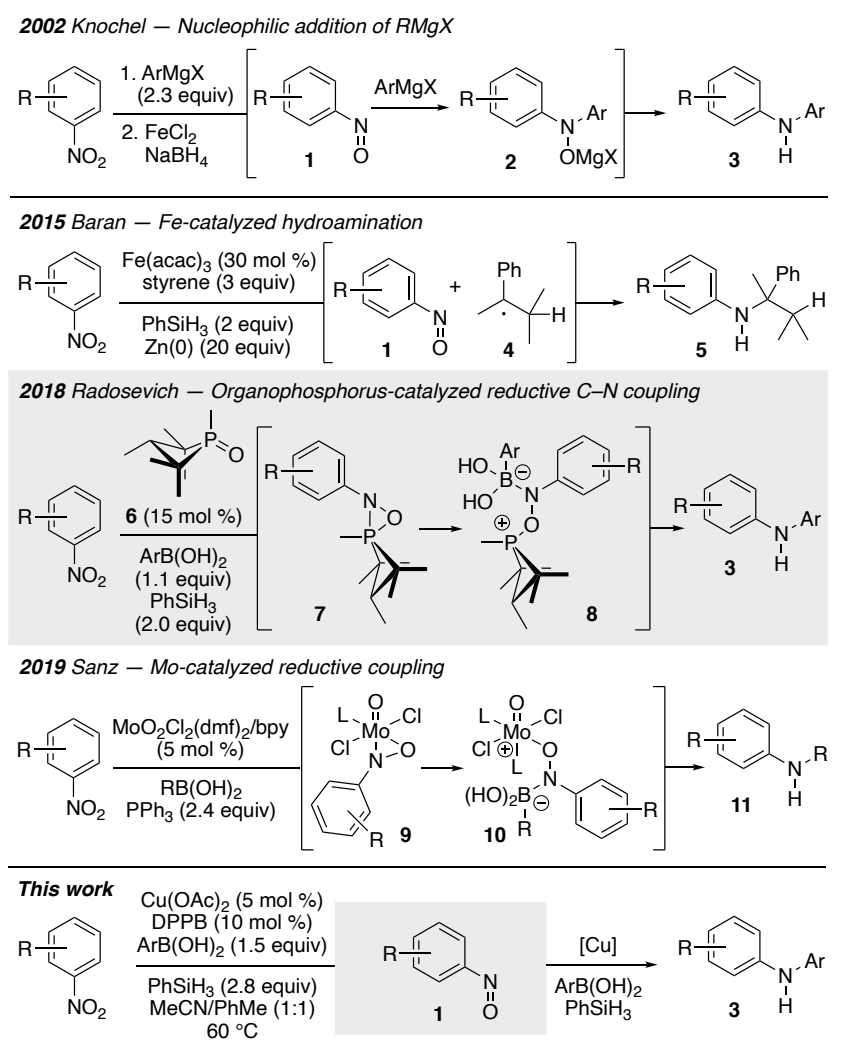

Scheme 1. Progress towards the development of efficient catalysis of cross-coupling reactions of nitroarenes to access diaryl amines.

To determine if a first-row transition metal catalyzed reductive cross-coupling reaction of nitroarenes and aryl boronic acids could be achieved we examined the reactivity of 4-methoxyphenylboronic acid and methyl-4-nitrobenzoate (Table 1). While only aniline formation was observed using an iron- or nickel catalyst, ${ }^{11}$ we found that the combination of $10 \mathrm{~mol} \%$ of $\mathrm{Cu}(\mathrm{OAc})_{2}$ and $\mathrm{DPPB}$ as the ligand afforded diaryl amine 3a, but reduction to aniline was observed to be competitive (entry 1). After control experiments established that both copper and the silane were required for the formation of diaryl amine 3a (entries 2 and 3), we turned our attention to improving the ratio of cross-coupling product 3a to aniline. We found that increasing the amount of diphosphine to copper to 2:1 reduced the amount of aniline significantly (entry 4). Using this ratio, the catalyst loading was investigated, and we observed that $5 \mathrm{~mol} \%$ of $\mathrm{Cu}(\mathrm{OAc})_{2}$ could be used without attenuating the ratio of 3a to aniline (entry 5). The catalyst could be reduced to as little as 2 mol \% without adversely affecting the reaction outcome (entry 6). While changing the counterion on copper did not have a positive effect on the cross-coupling reaction (entries $7-9),{ }^{11}$ reducing the temperature of the reaction to $60{ }^{\circ} \mathrm{C}$ improved the ratio of $3 \mathbf{a}$ to aniline to almost $2: 1$ (entry 10). At this temperature, we surveyed a range of co-solvents, ${ }^{11}$ and using a 1:1 mixture of acetonitrile and toluene produced $76 \%$ of 3a, which was accompanied by only $18 \%$ of aniline (entry 11 ). Using this solvent mixture and temperature, we found that changing the identity of the silane or ligand had a negative effect on the reaction outcome and did not improve the amount diaryl amine 3a formed (entries 12 - 17). The larger effect of changing the substituents on silane prompted us to examine the concentration of $\mathrm{PhSiH}_{3}$, and we found that using 2.8 equivalents of $\mathrm{PhSiH}_{3}$ afforded the highest ratio of diaryl amine 3a to aniline (entries 17 and 18). 
Table 1. Development of optimal conditions.

\begin{tabular}{|c|c|c|c|c|c|c|c|}
\hline 1 & $\mathrm{Cu}(\mathrm{OAc})_{2}(10)$ & DPPB (10) & $\mathrm{PhSiH}_{3}(3)$ & $\mathrm{MeCN}$ & 100 & 42 & 48 \\
\hline 3 & $\mathrm{Cu}(\mathrm{OAc})_{2}(10)$ & DPPB (10) & none & $\mathrm{MeCN}$ & 100 & 0 & 0 \\
\hline 4 & $\mathrm{Cu}(\mathrm{OAc})_{2}(10)$ & DPPB (20) & $\mathrm{PhSiH}_{3}(3)$ & $\mathrm{MeCN}$ & 100 & 52 & 28 \\
\hline 5 & $\mathrm{Cu}(\mathrm{OAc})_{2}(5)$ & DPPB (10) & $\mathrm{PhSiH}_{3}(3)$ & $\mathrm{MeCN}$ & 100 & 55 & 26 \\
\hline 9 & $\mathrm{CuSO}_{4}(5)$ & DPPB (10) & $\mathrm{PhSiH}_{3}(3)$ & $\mathrm{MeCN}$ & 100 & 36 & 34 \\
\hline 10 & $\mathrm{Cu}(\mathrm{OAc})_{2}(5)$ & DPPB (10) & $\mathrm{PhSiH}_{3}(3)$ & $\mathrm{MeCN}$ & 60 & 63 & 33 \\
\hline 11 & $\mathrm{Cu}(\mathrm{OAc})_{2}(5)$ & DPPB (10) & $\mathrm{PhSiH}_{3}(3)$ & MeCN/PhMe (1:1) & 60 & 76 & 18 \\
\hline 12 & $\mathrm{Cu}(\mathrm{OAc})_{2}(5)$ & DPPB (10) & $\mathrm{iPr}_{3} \mathrm{SiH}(4)$ & MeCN/PhMe (1:1) & 60 & 0 & 0 \\
\hline 13 & $\mathrm{Cu}(\mathrm{OAc})_{2}(5)$ & DPPB (10) & $(\mathrm{MeO})_{2} \mathrm{MeSiH}(3)$ & MeCN/PhMe (1:1) & 60 & 27 & 48 \\
\hline 14 & $\mathrm{Cu}(\mathrm{OAc})_{2}(5)$ & DPPP (10) & $\mathrm{PhSiH}_{3}(3)$ & MeCN/PhMe (1:1) & 60 & 55 & 27 \\
\hline 16 & $\mathrm{Cu}(\mathrm{OAc})_{2}(5)$ & 1,1-phen (10) & $\mathrm{PhSiH}_{3}(3)$ & MeCN/PhMe (1:1) & 60 & 0 & 90 \\
\hline 17 & $\mathrm{Cu}(\mathrm{OAc})_{2}(5)$ & DPPB (10) & $\mathrm{PhSiH}_{3}(2.8)$ & MeCN/PhMe (1:1) & 60 & 83 & 16 \\
\hline 18 & $\mathrm{Cu}(\mathrm{OAc})_{2}(5)$ & DPPB (10) & $\mathrm{PhSiH}_{3}(2.6)$ & MeCN/PhMe (1:1) & 60 & 80 & 20 \\
\hline
\end{tabular}

a As determined using ${ }^{1} \mathrm{H}$ NMR spectroscopy using $\mathrm{CH}_{2} \mathrm{Br}_{2}$ as the internal standard.

Using the optimal conditions, the scope and limitations of our $\mathrm{Cu}$-catalyzed reductive cross-coupling reaction was investigated with respect to the nitroarene (Table 2). The influence of electronic nature of the nitroarene on the reaction outcome was examined by changing the identity of the $\mathrm{R}^{1}$-substituent (entries $1-6$ ). We found the reaction worked best with electron-deficient nitroarenes, but diaryl amines could be accessed from nitrobenzene albeit with a diminished yield. Electron-rich nitroarenes, however, such as 4-nitroanisole resulted in no reaction (entry 5). This result could be leveraged by using 1,4-dinitrobenzene, which resulted in coupling of the aryl boronic acid to only one of the two nitro groups to produce 3f, albeit in a slightly attenuated yield (entry 6). The effect of meta-substitution was investigated, and diaryl amines $\mathbf{3 g}-\mathbf{3 i}$ were formed in good yield irrespective of whether the $\mathrm{R}^{2}$-substituent was a $\mathrm{F}_{3} \mathrm{C}$-, Me- or MeO-group (entries 7 10). To our surprise, the cross-coupling reaction exhibited a broad tolerance to the identity of the ortho-substituent (entries 10 - 14): high yields of diaryl amine 3 were obtained with a potentially coordinating nitrile $\mathrm{R}^{3}$-substituent, an alkyl group and even an electron-donating methoxy $\mathrm{R}^{3}$-substituent, which inhibited the reaction when it was present in the para-position. The success of nitroarene $\mathbf{3} \mathbf{j}$ spurred us to examine other potentially coordinating heteroarenes, and we were delighted to see that 3-nitropyridines were competent substrates enabling access to 3p (entry 16). These results illustrate that diaryl amines can be efficiently formed from a broad range of nitroarenes and heteroarenes. 
Table 2. Scope and limitations with regards to the nitroarene.

\begin{tabular}{|c|c|c|c|c|c|}
\hline (1 equiv) & (1.5 equiv) & $\begin{array}{r}\mathrm{Cu}(\mathrm{C} \\
\mathrm{DPI} \\
\mathrm{PhS} \\
\mathrm{MeCN} /\end{array}$ & $\begin{array}{l}\begin{array}{l}5 \mathrm{~mol} \%) \\
\mathrm{mol} \%)\end{array} \\
\underset{8 \text { equiv) }}{(1: 1,0.1 \mathrm{M})} \\
30 \mathrm{~h}\end{array}$ & & \\
\hline entry & $\mathrm{R}^{1}$ & $\mathrm{R}^{2}$ & $\mathrm{R}^{3}$ & 3 & yield, \%a \\
\hline 1 & $\mathrm{MeO}_{2} \mathrm{C}$ & $\mathrm{H}$ & $\mathrm{H}$ & $\mathbf{a}$ & $83(81)^{b}$ \\
\hline 2 & $\mathrm{~F}_{3} \mathrm{C}$ & $\mathrm{H}$ & $\mathrm{H}$ & b & 84 \\
\hline 3 & $\mathrm{Cl}$ & $\mathrm{H}$ & $\mathrm{H}$ & c & 85 \\
\hline 4 & $\mathrm{H}$ & $\mathrm{H}$ & $\mathrm{H}$ & d & 66 \\
\hline 5 & $\mathrm{MeO}$ & $\mathrm{H}$ & $\mathrm{H}$ & e & n.r. \\
\hline 6 & $\mathrm{O}_{2} \mathrm{~N}$ & $\mathrm{H}$ & $\mathrm{H}$ & $f$ & 59 \\
\hline 7 & $\mathrm{H}$ & $\mathrm{F}_{3} \mathrm{C}$ & $\mathrm{H}$ & g & 89 \\
\hline 8 & $\mathrm{H}$ & $\mathrm{Me}$ & $\mathrm{H}$ & $\mathbf{h}$ & 73 \\
\hline 9 & $\mathrm{H}$ & $\mathrm{MeO}$ & $\mathrm{H}$ & $\mathbf{i}$ & 85 \\
\hline 10 & $\mathrm{H}$ & $\mathrm{H}$ & $\mathrm{NC}$ & j & 83 \\
\hline 11 & $\mathrm{H}$ & $\mathrm{H}$ & $\mathrm{F}_{3} \mathrm{C}$ & $\mathbf{k}$ & 77 \\
\hline 12 & $\mathrm{H}$ & $\mathrm{H}$ & $\mathrm{Br}$ & I & 89 \\
\hline 13 & $\mathrm{H}$ & $\mathrm{H}$ & Et & m & 82 \\
\hline 14 & $\mathrm{H}$ & $\mathrm{H}$ & OMe & $\mathbf{n}$ & 72 \\
\hline 15 & $-\mathrm{HC}=\mathrm{CH}-\mathrm{Cr}$ & $=\mathrm{CH}-$ & $\mathrm{H}$ & o & 96 \\
\hline 16 & & & & p & 75 \\
\hline
\end{tabular}

a Isolated after silica gel chromatography. ${ }^{b} 1 \mathrm{mmol}$ reaction scale.

The scope with regards to the aryl boronic acid was also surveyed (Table 3). Modifying the electronic nature of the aryl boronic acid was investigated by examining the effect of a variety of $\mathrm{R}^{1}$ - and $\mathrm{R}^{2}$-substituents on the cross-coupling reaction (entries 1 -7), and we observed that the yield of 12 was high irrespective of whether the substituent was an electrondonating- or an electron-withdrawing group. The only exception was the attenuated yield of $\mathbf{1 2 d}$ obtained when the aryl boronic acid contained a thiomethyl $\mathrm{R}^{1}$-substituent. In contrast, the cross-coupling reaction was sensitive to the identity of the ortho-substituent. While a methoxy substituent was tolerated, no diaryl amine was formed from an aryl boronic acid bearing an ethyl $\mathrm{R}^{1}$-substituent (entries 8 and 9). While this effect could be attributed to the increased steric environment around the reaction center, we found 1-napthylboronic acid to be a good partner to afford diaryl amine $\mathbf{1 2} \mathbf{j}$ (entry 10). Our cross-coupling reaction also tolerated a coordinating heterocycle in the boronic acid component to afford 2-pyrimidine amine 12k, albeit in an attenuated yield in comparison to pyridyl $\mathbf{3 p}$ (entry 11). 
Table 3. Scope and limitations with regards to the boronic acid.

\begin{tabular}{|c|c|c|c|c|c|}
\hline $\mathrm{CO}_{\substack{\mathrm{CO}_{2} \mathrm{Me} \\
\text { (1 equiv) }}}^{\mathrm{NO}_{2}}$ & (1.5 equiv) & $\begin{array}{r}\mathrm{Cu}(\mathrm{O} \\
\mathrm{DPP} \\
\mathrm{PhSi} \\
\mathrm{MeCN} / \mathrm{P} \\
6\end{array}$ & 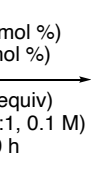 & $\mathrm{D}_{2} \mathrm{C}^{\prime}$ & (N) \\
\hline entry & $\mathrm{R}^{1}$ & $\mathrm{R}^{2}$ & $\mathrm{R}^{3}$ & 13 & yield, \%a \\
\hline 1 & $\mathrm{~F}_{3} \mathrm{C}$ & $\mathrm{H}$ & $\mathrm{H}$ & $\mathbf{a}$ & 90 \\
\hline 2 & $\mathrm{~F}$ & $\mathrm{H}$ & $\mathrm{H}$ & b & 97 \\
\hline 3 & $\mathrm{Me}$ & $\mathrm{H}$ & $\mathrm{H}$ & c & 90 \\
\hline 4 & MeS & $\mathrm{H}$ & $\mathrm{H}$ & d & 64 \\
\hline 5 & $\mathrm{H}$ & $\mathrm{F}$ & $\mathrm{H}$ & e & 88 \\
\hline 6 & $\mathrm{H}$ & $\mathrm{MeO}$ & $\mathrm{H}$ & f & 92 \\
\hline 7 & $\mathrm{H}$ & $\mathrm{Me}$ & $\mathrm{H}$ & g & 88 \\
\hline 8 & $\mathrm{H}$ & $\mathrm{H}$ & $\mathrm{MeO}$ & $\mathbf{h}$ & 85 \\
\hline 9 & $\mathrm{H}$ & $\mathrm{H}$ & Et & $\mathbf{i}$ & n.r. \\
\hline 10 & $\mathrm{H}$ & \multicolumn{2}{|c|}{$-\mathrm{HC}=\mathrm{CH}-\mathrm{CH}=\mathrm{CH}-$} & $\mathbf{j}$ & 83 \\
\hline 11 & \multicolumn{3}{|c|}{$(\mathrm{OH})_{2}$} & k & 59 \\
\hline
\end{tabular}

To provide insight into the mechanism of the reaction, several control experiments were performed (Scheme 2). To validate that the cross-coupling reactions proceeded via a nitrosoarene intermediate, an excess of 2,3-dimethylbutadiene was added to the reaction of 4-methylcarboxylate-nitrobenzene and 4-methoxyphenyl boronic acid, and oxazine 13 was isolated in $44 \% .{ }^{12}$ The absence of diarylamine and modest aniline formation indicates that the nitrosoarene intermediate is intercepted preferentially by the diene before reduction or cross-coupling can occur. Because anilines are well established as competent substrates for $\mathrm{C}-\mathrm{N}$ bond cross-coupling reactions, ${ }^{13}$ we were curious to determine if $\mathrm{C}-\mathrm{NAr}$ bond formation in our reaction occurred via a nitrosoarene or aniline. While no diarylamine formation was obtained using an aniline, submission of nitrosoarene $\mathbf{1 4}$ to reaction conditions afforded diaryl amine $\mathbf{3 q}$ in $\mathbf{5 6 \%}$. Our data suggests that copper is required to trigger $\mathrm{C}-\mathrm{NAr}$ bond formation. No reaction was observed when copper acetate was omitted from the reaction of nitrosoarene $\mathbf{1 5}$ and the aryl boronic acid. Our investigations also uncovered that the hydroxyl substituent of the aryl boronic acid plays a critical role for a successful reaction outcome. When an aryl boronic pinacolate ester or an aryl trifluoroborate were submitted to reaction conditions only reduction to aniline was observed. 


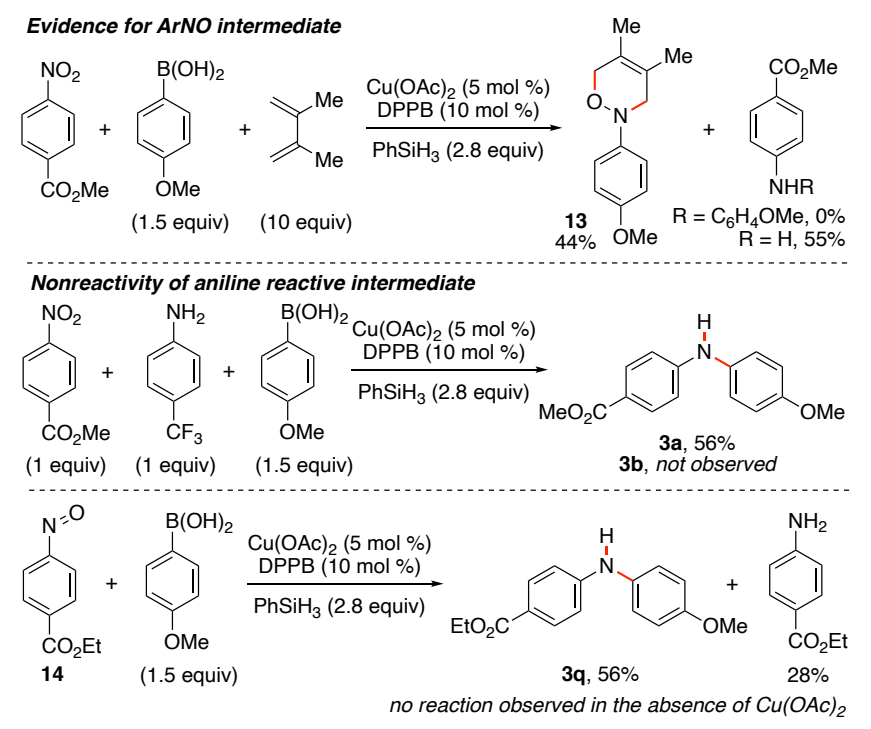

Critical nature of boronic acid hydroxy substituents

Together these experiments suggest that the catalytic cycle for this cross-coupling reaction requires the copper catalyst for both the deoxygenation and C-NAr bond formation (Scheme 3). Deoxygenation of nitroarene by a copper hydride produces nitrosoarene and a copper hydroxide, which is reduced by silane. ${ }^{14}$ The observation of oxazine 13 when $2,3-$ dimethylbutadiene is present suggests that the nitrosoarene dissociates from the copper hydroxide complex before the subsequent $\mathrm{C}-\mathrm{NAr}$ bond forming steps. If the copper remained coordinated to ArNO then only a nitroso-ene product would have been observed. ${ }^{15}$ Our control experiments indicate that copper also catalyzes the carbon-nitrogen bond formation. This could occur through coordination of copper to either the aryl boronic acid to form $\mathbf{1 5}$ or via copper nitrosoarene $\mathbf{1 6 .}{ }^{16,15}$ Reaction with the coupling partner-ArNO 1 or $\mathrm{ArB}(\mathrm{OH})_{2}$ - forms metallocycle 17, ${ }^{17}$ which triggers a 1,2-aryl shift to establish the $\mathrm{C}-\mathrm{N}$ bond and produce 18. Reduction of 18 with either copper hydride or silane produces the diaryl amine and regenerates the copper catalyst. ${ }^{18}$

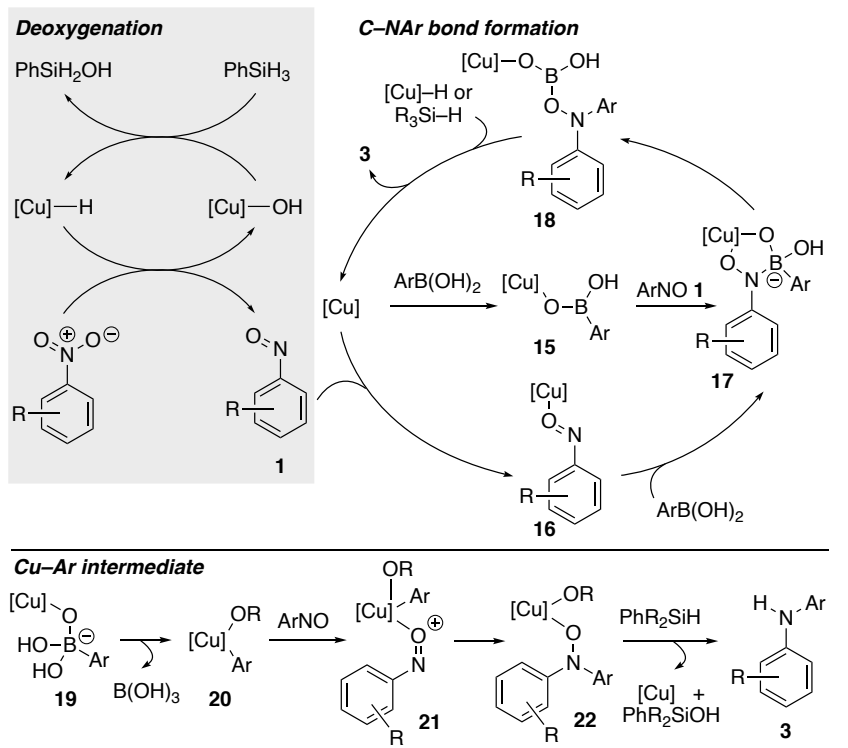

Scheme 3. Potential catalytic cycle. 
Alternatively, C-NAr bond formation could occur through a mechanism similar to the Chan-Evans-Lam reaction. Coordination of the aryl boronic acid to the copper hydroxide substituent affords 19, which triggers transmetalation to produce $\mathrm{Cu}(\mathrm{II})$ intermediate $\mathbf{2 0}$ and boric acid. Coordination of nitrosoarene $\mathbf{1}$ affords $\mathbf{2 1}$, which undergoes a 1,2 insertion to produce 22. Reduction of $\mathbf{2 2}$ with silane produces diaryl amine $\mathbf{3}$ and regenerates the copper catalyst. This mechanism appears less likely because formation of copper aryl species $\mathbf{2 0}$ should occur for aryl boronic pinacolate esters or trifluoroborate salts. ${ }^{19}$

In conclusion, we have discovered a mild copper-catalyzed reaction that couples nitroarenes or nitroheteroarenes and aryl boronic acids using phenyl silane as the stoichiometric reductant. Our reaction requires as little as 2 mol \% of copper and tolerates a broad range of functionality on both the nitroarene and aryl boronic acid to furnish the amine product. Our preliminary mechanistic investigations reveal that the cross-coupling reaction proceeds via a nitrosoarene intermediate and that copper is required for to catalyzed both the deoxygenation and the $\mathrm{C}-\mathrm{NAr}$ bond forming steps.

ACKNOWLEDGMENT. We are grateful to the National Institutes of Health, NIGMS (R01GM138388) and the National Science Foundation (CHE-1564959) for their generous financial support. We thank Mr. Furong Sun (UIUC) for high resolution mass spectrometry data.

\section{REFERENCES.}

1. (a) Knölker, H.-J.; Reddy, K. R.; Cordell, G. A., Ed.; Academic Press: Amsterdam, 2008, p 1. (b) Welsch, M. E.; Snyder, S. A.; Stockwell, B. R. Privileged Scaffolds for Library Design and Drug Discovery. Curr. Opin. Chem. Biol. 2010, 14, 347. (c) Vitaku, E.; Smith, D. T.; Njardarson, J. T. Analysis of the Structural Diversity, Substitution Patterns, and Frequency of Nitrogen Heterocycles among U.S. FDA Approved Pharmaceuticals. J. Med. Chem. 2014, $57,10257$.

2. (a) Liang, M.; Chen, J. Arylamine Organic Dyes for Dye-Sensitized Solar Cells. Chem. Soc. Rev. 2013, 42, 3453. (b) Wang, J.; Liu, K.; Ma, L.; Zhan, X. Triarylamine: Versatile Platform for Organic, Dye-Sensitized, and Perovskite Solar Cells. Chem. Rev. 2016, 116, 14675.

3. (a) Jiang, L.; Buchwald, S. L. In Metal-Catalyzed Cross-Coupling Reactions 2004, p 699. (b) Hartwig, J. F. CarbonHeteroatom Bond Formation Catalysed by Organometallic Complexes. Nature 2008, 455, 314. (c) Bariwal, J.; Van der Eycken, E. C-N Bond Forming Cross-Coupling Reactions: An Overview. Chem. Soc. Rev. 2013, 42, 9283. (d) Sambiagio, C.; Marsden, S. P.; Blacker, A. J.; McGowan, P. C. Copper Catalysed Ullmann Type Chemistry: From Mechanistic Aspects to Modern Development. Chem. Soc. Rev. 2014, 43, 3525. (e) Corcoran, E. B.; Pirnot, M. T.; Lin, S.; Dreher, S. D.; DiRocco, D. A.; Davies, I. W.; Buchwald, S. L.; MacMillan, D. W. C. Aryl Amination Using LigandFree Ni(II) Salts and Photoredox Catalysis. Science 2016, 353, 279. (f) Ruiz-Castillo, P.; Buchwald, S. L. Applications of Palladium-Catalyzed C-N Cross-Coupling Reactions. Chem. Rev. 2016, 116, 12564. (g) Dorel, R.; Grugel, C. P.; Haydl, A. M. The Buchwald-Hartwig Amination After 25 Years. Angew. Chem. Int. Ed. 2019, 58, 17118. (h) West, M. J.; Fyfe, J. W. B.; Vantourout, J. C.; Watson, A. J. B. Mechanistic Development and Recent Applications of the Chan-Lam Amination. Chem. Rev. 2019, 119, 12491.

4. (a) Jana, N.; Zhou, F.; Driver, T. G. Promoting Reductive Tandem Reactions of Nitrostyrenes with $\mathrm{Mo}(\mathrm{CO})_{6}$ and a Palladium Catalyst To Produce $3 H$-Indoles. J. Am. Chem. Soc. 2015, 137, 6738. (b) Zhou, F.; Wang, D.-S.; Guan, X.; Driver, T. G. Nitroarenes as the Nitrogen Source in Intermolecular Palladium-Catalyzed Aryl C-H Bond Aminocarbonylation Reactions. Angew. Chem. Int. Ed. 2017, 56, 4530. (c) Shevlin, M.; Guan, X.; Driver, T. G. IronCatalyzed Reductive Cyclization of $o$-Nitrostyrenes Using Phenylsilane as the Terminal Reductant. ACS Catal. 2017, 5518. (d) Ford, R. L.; Alt, I.; Jana, N.; Driver, T. G. Intramolecular Pd-Catalyzed Reductive Amination of Enolizable $\mathrm{sp}^{3}$-C-H Bonds. Org. Lett. 2019, 21, 8827.

5. Sapountzis, I.; Knochel, P. A New General Preparation of Polyfunctional Diarylamines by the Addition of Functionalized Arylmagnesium Compounds to Nitroarenes. J. Am. Chem. Soc. 2002, 124, 9390.

6. Niggemann and co-workers demonstrated that secondary aryl amines could be formed through the addition of alkylor aryl zinc reagents to a nitrenoid generated in situ from a $\mathrm{B}_{2}$ pin $_{2}$-mediated reduction of nitroarenes. See: Rauser, M.; Ascheberg, C.; Niggemann, M. Electrophilic Amination with Nitroarenes. Angew. Chem. Int. Ed. 2017, 56, 11570. 
7. Gui, J.; Pan, C.-M.; Jin, Y.; Qin, T.; Lo, J. C.; Lee, B. J.; Spergel, S. H.; Mertzman, M. E.; Pitts, W. J.; La Cruz, T. E.; Schmidt, M. A.; Darvatkar, N.; Natarajan, S. R.; Baran, P. S. Practical Olefin Hydroamination with Nitroarenes. Science 2015, 348, 886.

8. (a) Cheung, C. W.; Ploeger, M. L.; Hu, X. Direct Amidation of Esters with Nitroarenes. Nat. Commun. 2017, 8, 14878. (b) Cheung, C. W.; Ploeger, M. L.; Hu, X. Nickel-Catalyzed Reductive Transamidation of Secondary Amides with Nitroarenes. ACS Catal. 2017, 7, 7092.

9. (a) Nykaza, T. V.; Cooper, J. C.; Li, G.; Mahieu, N.; Ramirez, A.; Luzung, M. R.; Radosevich, A. T. Intermolecular Reductive $\mathrm{C}-\mathrm{N}$ Cross Coupling of Nitroarenes and Boronic Acids by PIII/PV=O Catalysis. J. Am. Chem. Soc. 2018, 140, 15200. (b) Li, G.; Nykaza, T. V.; Cooper, J. C.; Ramirez, A.; Luzung, M. R.; Radosevich, A. T. An Improved $\mathrm{PIII} / \mathrm{PV}=\mathrm{O}-$ Catalyzed Reductive $\mathrm{C}-\mathrm{N}$ Coupling of Nitroaromatics and Boronic Acids by Mechanistic Differentiation of Rate- and Product-Determining Steps. J. Am. Chem. Soc. 2020, 142, 6786.

10. Suárez-Pantiga, S.; Hernández-Ruiz, R.; Virumbrales, C.; Pedrosa, M. R.; Sanz, R. Reductive Molybdenum-Catalyzed Direct Amination of Boronic Acids with Nitro Compounds. Angew. Chem. Int. Ed. 2019, 58, 2129.

11. Refer to the Supporting Information for more details.

12. For leading reports using a diene to trap a nitrosoarene reactive intermediate, see: (a) Oikawa, E.; Tsubaki, S. The Structure of the Crystalline Adduct of Nitrosobenzene and 2,3-Dimethyl-1,3-butadiene. Bull. Chem. Soc. Jpn. 1973, 46, 1819. (b) Taylor, E. C.; Tseng, C. P.; Rampal, J. B. Conversion of a Primary Amino Group into a Nitroso Group. Synthesis of Nitroso-Substituted Heterocycles. J. Org. Chem. 1982, 47, 552.

13. cf. (a) Ullmann, F. Ueber Eine Neue Bildungsweise von Diphenylaminderivaten. Ber. Dtsch. Chem. Ges. 1903, 36, 2382. (b) Wolfe, J. P.; Wagaw, S.; Buchwald, S. L. An Improved Catalyst System for Aromatic Carbon-Nitrogen Bond Formation: The Possible Involvement of Bis(Phosphine) Palladium Complexes as Key Intermediates. J. Am. Chem. Soc. 1996, 118, 7215. (c) Driver, M. S.; Hartwig, J. F. A Second-Generation Catalyst for Aryl Halide Amination: Mixed Secondary Amines from Aryl Halides and Primary Amines Catalyzed by (DPPF)PdCl ${ }_{2} . J . A m$. Chem. Soc. 1996, 118, 7217. (d) Chan, D. M. T.; Monaco, K. L.; Wang, R.-P.; Winters, M. P. New $N$ - and $O$-arylations with Phenylboronic Acids and Cupric Acetate. Tetrahedron Lett. 1998, 39, 2933. (e) Yoo, W.-J.; Tsukamoto, T.; Kobayashi, S. Visible-Light-Mediated Chan-Lam Coupling Reactions of Aryl Boronic Acids and Aniline Derivatives. Angew. Chem. Int. Ed. 2015, 54, 6587.

14. Control experiments established that no nitrosoarene was formed in the absence of copper acetate or phenylsilane, see the Supporting Information for more details.

15. For reports of copper nitrosoarene complexes, see: (a) Srivastava, R. S.; Khan, M. A.; Nicholas, K. M. Nitrosoarene- $\mathrm{Cu}(\mathrm{I})$ Complexes Are Intermediates in Copper-Catalyzed Allylic Amination. J. Am. Chem. Soc. 2005, 127, 7278. (b) Srivastava, R. S.; Tarver, N. R.; Nicholas, K. M. Mechanistic Studies of Copper(I)-Catalyzed Allylic Amination. J. Am. Chem. Soc. 2007, 129, 15250.

16. Coordination of the aryl boronic acid to a copper hydroxide substituent has been proposed in $\mathrm{Cu}$-catalyzed ChanEvans-Lam reaction, see: (a) King, A. E.; Ryland, B. L.; Brunold, T. C.; Stahl, S. S. Kinetic and Spectroscopic Studies of Aerobic Copper(II)-Catalyzed Methoxylation of Arylboronic Esters and Insights into Aryl Transmetalation to Copper(II). Organometallics 2012, 31, 7948. (b) Vantourout, J. C.; Miras, H. N.; Isidro-Llobet, A.; Sproules, S.; Watson, A. J. B. Spectroscopic Studies of the Chan-Lam Amination: A Mechanism-Inspired Solution to Boronic Ester Reactivity. J. Am. Chem. Soc. 2017, 139, 4769. (c) Hardouin Duparc, V.; Bano, G. L.; Schaper, F. Chan-Evans-Lam Couplings with Copper Iminoarylsulfonate Complexes: Scope and Mechanism. ACS Catal. 2018, 8, 7308.

17. Coordination of the aryl boronic acid to the nitrogen of the nitrosobenzene was proposed as a catalytic intermediate by both Radosevich and Sanz, see: ref $9 b$ and ref 10.

18. For copper-catalyzed reduction of $\mathrm{Ar}_{2} \mathrm{~N}-\mathrm{OH}$, see: Golubev, V. A.; Sen', V. D. Preparative Syntheses of Bis(4-tertbutylphenyl)aminoxyl. Russ. J. Org. Chem. 2013, 49, 555.

19. For the use of ArBpin or $\mathrm{ArBF}_{3} \mathrm{~K}$ reagents in Chan-Evans-Lam reactions, see: (a) Quach, T. D.; Batey, R. A. Ligandand Base-Free Copper(II)-Catalyzed C-N Bond Formation: Cross-Coupling Reactions of Organoboron Compounds with Aliphatic Amines and Anilines. Org. Lett. 2003, 5, 4397. (b) Tzschucke, C. C.; Murphy, J. M.; Hartwig, J. F. Arenes to Anilines and Aryl Ethers by Sequential Iridium-Catalyzed Borylation and Copper-Catalyzed Coupling. Org. Lett. 2007, 9, 761. (c) Sueki, S.; Kuninobu, Y. Copper-Catalyzed N- and O-Alkylation of Amines and Phenols using Alkylborane Reagents. Org. Lett. 2013, 15, 1544. (d) Joliton, A.; Carreira, E. M. Novel SF 5 -Anilines and SF5-Aryl Ethers from $\mathrm{SF}_{5}$-Substituted Potassium Aryl Trifluoroborates. Synlett 2015, 26, 737. (e) Vantourout, J. C.; Law, R. P.; 
Isidro-Llobet, A.; Atkinson, S. J.; Watson, A. J. B. Chan-Evans-Lam Amination of Boronic Acid Pinacol (BPin) Esters: Overcoming the Aryl Amine Problem. J. Org. Chem. 2016, 81, 3942. 